\title{
The elephant in the room: \\ Critical management studies conferences as a site of body pedagogics
}

\author{
Emma Bell \\ University of Bath, UK

\section{Daniel King} \\ Nottingham Trent University, UK
}

\begin{abstract}
This article explores conferences as an inter-corporeal space wherein body pedagogics are enacted, enabling the acquisition of techniques, skills and dispositions that allow newcomers to demonstrate their proficiency as members of a culture. The bodies of conference participants constitute the surface onto which culture is inscribed, these normalizing practices enabling academic power relations to be constructed and identities internalized.An autoethnographic analysis of critical management studies (CMS) conferences forms the basis for identification of the bodily dispositions of control and endurance which characterize the proficient CMS academic. The article considers the potential silencing effects associated with these practices that generate a between-men culture that excludes difference and reinforces patriarchal values. It concludes by reviewing the implications of body pedagogics for understanding how other organizational cultures are constructed.
\end{abstract}

\section{Keywords}

Autoethnography; conferences; critical management studies; embodiment; power

\section{Introduction}

The role of the body as a medium through which cultural norms and values are acquired remains a relatively unexplored aspect of organizational learning. Academics may be seen as a professional organizational group that is particularly reluctant to acknowledge or reflect upon the embodied aspects of their collective identity practices. The dichotomous and hierarchical opposition that exists between mind and body intellect and emotion within academia presents the character of the ideal academic in a way which suppresses and subordinates the concept of the body through defining it negatively as unnecessary, intrusive or incidental. This Cartesian mind/body bifurcation is further associated with the binary opposition between male and female; the coupling of mind and maleness, 
body and femaleness providing a correlation that is central to the way philosophy has developed historically and continues to be practised today (Grosz, 1994; Martin, 2000). The marginalization of the body has significant consequences for understanding how academic cultures are constructed.

This article focuses on the role of the body in the construction of the critical management studies (CMS) academic, conceptualizing it as the 'medium' by which the individual 'comes to enter into' this 'collectively inhabited world' (Lande, 2007: 97). We propose that CMS can be understood as a culture characterized by certain distinctive and shared practices. Whilst this culture is undoubtedly heterogeneous and pluralistic, comprising various competing and conflicting perspectives (Fournier and Grey, 2000), it has become sufficiently cohesive to be discernable (Clegg et al., 2006; Parker, 2002) and therefore analysed. The article explores the process of bodily learning whereby proficiency as a member of this culture is acquired and appropriate skills and dispositions are demonstrated, often through achievement in a test of endurance and expertise. The body is thus the surface onto which the culture is inscribed and the vehicle for its reproduction through enabling the interiorization of ethical values that guide behaviour in situations of face-to-face interaction.

We suggest that conferences constitute a central pedagogic means through which these bodily techniques are transmitted and the subjectivities of cultural members enacted. We analyse the role of conferences in subjecting individuals to normative evaluation and regulation. Through our experiences of acquiring, or failing to acquire, the embodied attributes and skills associated with the proficient CMS academic, we explore the potentially homogenizing and normalizing effects associated with these practices. The article thus constitutes an ethnographic investigation into a culture in which we are participants.

Much has been said about the intellectual principles that differentiate critical from mainstream management studies (Clegg et al., 2006; Fournier and Grey, 2000; Reedy, 2008; Walsh and Weber, 2002 ). However, far less attention has been paid to the ritual and bodily practices that characterize CMS, including the processes of socialization whereby certain identities are constructed and communicated. It must be acknowledged that the pursuit of self-understanding is not well established among academics (Butterwick and Dawson, 2005). However, we might expect this dynamic to be less pronounced within CMS since one of the centrally defining characteristics of CMS is a commitment to reflexivity in teaching (Fulop, 2002; Reynolds, 1999; Reynolds and Trehan, 2001) and research (Alvesson and Sköldberg, 2000). Furthermore, if the purpose of CMS is to raise awareness of power, inequality and exploitation in other organizations, we suggest it is necessary to explore what may be excluded, effaced or damaged through the culture's own power relationships (Wray-Bliss, 2003, 2004). For 'if we do not speak publicly about, and critically examine, the problematic conditions of life and work within our own academic walls, then our credibility as critics and analysts of what is going on in the world outside... is bound to be similarly diminished' (Butterwick and Dawson, 2005: 52).

\section{Insider accounts of academic conferences}

Despite their potential significance as processes of collective identity formation, the role of conferences as a means of socialization into academic cultures is rarely considered. Instead much of the literature highlights the practical benefits that accrue from attending conferences as an opportunity for job seekers, a forum for presenting ideas and receiving feedback and a means of keeping up to date with recent developments in a field (Blaxter et al., 1998; Rugg and Petre, 2004). We must instead turn to novels and autobiographical accounts of academic life (Showalter, 2005), rather than academic analyses, to gain insight into the body habits, skills and techniques that academics use to demonstrate their proficiency in social relationships. For example, novelist and academic 
David Lodge (1985) portrays academic conferences as a setting for bodily pain-involving excessive amounts of coffee, bad food and uncomfortable surroundings, and pleasure-offering opportunities for delegates to party, get drunk and get laid. Other autobiographical accounts emphasize the gendered synergy between physical and intellectual strength, made manifest through practices of intimidation and bullying (McCloskey, 1999).

In recent years however, there have been a number of reflexive insider analyses of conferences written by business school academics. This suggests an emerging intellectual interest in exploring the power relations associated with these cultural practices. Spicer (2005) provides a brief insight into the physical as well as emotional experience of attending conferences, describing them as sites of 'Indifferent food... Extra-marital affairs. Verbal violence. Arrogant grunts. Closed circles. Dashed hopes. Petty promotionalism. Scholastic policing. Grinding headaches. Boredom. Body pain' (Spicer, 2005: 21). Knights (2006) reflects upon the gendered nature of his experience of academic conferences, including their 'gladiatorial character' and masculine atmosphere where 'subjects (not necessarily exclusively male) show their prowess in aggressively competitive conduct with one another' and display a 'cockfighting mentality' (Knights, 2006: 712).

New and Fleetwood (2006) provide a more sustained analysis that suggests women are more likely to be disadvantaged as a result of the cultural preference towards masculine styles in paper presentations and discussions. Men are more likely to display confident, combative or intimidating behaviour, speaking fast, interrupting and sometimes making long contributions only loosely connected to the theme, whereas women show a greater propensity towards use of self-deprecating language and hedging phrases. Women are less likely to speak and more likely to engage in selfcensorship and environmental checking before doing so, in a desire to avoid participating in domineering or 'space grabbing' behaviour. Furthermore if women adopt the styles preferred by men they are more likely to be judged negatively, whereas 'men on the other hand may safely adopt the quieter, inquiring, non-combative styles usually considered feminine, since by participating in the academy as part of the public realm, they are already expressing an acceptable version of masculinity' (New and Fleetwood, 2006: 89).

The different subject positions of men and women is also commented on by Ford and Harding (forthcoming), who argue that conferences gender participants in ways that perpetuate imbalances of power between male and female professionals. These cultural norms position women as belonging to the domestic, private sphere and marginalize them within the public space of the conference. They show how this constructs the conference as a hostile public space in which women are subjected to processes of infantilization and seduction that define them as subordinate and inferior. However, there is always the possibility of resistance; Ford and Harding explain that their motivation in analysing conferences arose from the experience of attending them and their attempts to resist these discourses through collective action.

We became particularly interested in conferences as gendered experiences following an occasion when we were part of a group of women who registered their discomfort at a critical management studies conference several years ago. At that conference, the aggressively macho culture felt so oppressive that women were silenced and felt ridiculed, but grouped together to organise support and resistance. (Ford and Harding, forthcoming)

Humphreys and Learmonth (2009) analyse their own experience of attending conferences using autobiographical vignettes to record their impressions of, and reflections on, attending two quite different academic conferences. These authors highlight the disjuncture between the ideals that attracted them to academic careers in the first place and the instrumental, careerist behaviours that 
contemporary university performance regimes encourage. They also recognize aspects of their own behaviour as self-seeking, thereby revealing the self-doubts and worries associated with the construction of an appropriate academic identity. Another confessional tale (Van Maanen, 1988) is provided by Humphreys (2005) who reflects on his experience of attending an Academy of Management conference, where his fear as an emerging scholar presenting his first paper was significant. 'For a couple of days, not only had I been surrounded by academics whose work I had read and cited but now some of them were members of my audience as well. I felt like a charlatan' (Humphreys, 2005: 847). For Humphreys this is the beginning of a career transformation into an authoritative performer who responds well under pressure.

As these accounts illustrate, conferences constitute a key site of academic socialization that enables norms and values to be passed on from experts to newcomers. They thus provide a material means of inscribing regimes of cultural power onto the embodied subject.

\section{Studying the agonizingly familiar}

Our interest in CMS culture arose from the dis-ease we experienced when participating in conferences. Although certain superficial cultural practices distinguish CMS conferences from the mainstream-CMS is no place for the smart suit, well-polished CV or business card (Burrell, 1993)—we experienced the power relations that characterized CMS conferences as more competitive, aggressive and masculine than their mainstream equivalents. While these dynamics were most obvious at the main conference, we observed similar practices at other CMS events, including smaller seminars and tracks at other conferences.

Active participation in a culture is suggested by sociologists of the body to be crucial in enabling understanding of the processes through which social actors become proficient. Because such practices of bodily inscription exist beyond the level of discursive awareness and propositional reasoning (Lande, 2007; Wacquant, 2005), traditional methods of qualitative research such as interviewing are of limited value in studying them. We therefore decided to conduct a self-ethnography, 'a study and a text in which the researcher-author describes a social setting to which s/he has a "natural access", is an active participant, more or less on equal terms with other participants' (Alvesson, 2003: 174). Alvesson proposes the method of self-ethnography, which is closely related to autoethnography (Ellis, 2004; Ellis and Bochner, 2000; Hayano, 1979), as a means of studying university contexts that the researcher is very familiar with, personal involvement enabling greater physical and metaphorical closeness to certain social practices.

Through becoming attentive to our own embodied experiences we began to develop insider accounts (Brannick and Coghlan, 2007) based on lived experience that enabled us to turn familiar situations into objects of study (Riemer, 1977). Our attention thus turned from the dramatically different 'them' and towards the agonizingly familiar 'us' (Spradley and McCurdy, 1973). We relied on participation rather than research-focused observation as our principal data source (Alvesson, 2003). Hence, we did not participate in the conferences with the instrumental aim of collecting data; instead the research only became a preoccupation retrospectively, at the point when we began to subject our experiences to close scrutiny and writing. Only then did personal accounts of our own experience as members of the academic tribe (Becher and Trowler, 1989) we were studying become the empirical basis for cultural and political reflection in 'a back-and-forth movement between experiencing and examining a vulnerable self and observing and revealing the broader context of that experience' (Ellis, 2007: 14).

Initially we wrote separate narratives, treating our personally remembered experiences of attending CMS conferences as a source of primary data (Ellis and Bochner, 1992). Then we read 
each other's stories, discussed them and 'co-constructed a version that represented our joint experiences' (Ellis, 2007: 21). Next, we 'performed' our stories (Ellis and Bochner, 1992) at seminars, using expressions and gestures to make the embodied nature of our experiences explicit. We also invited participants to add to our stories, subsequently incorporating their comments into our dialogical narrative. Through this approach we sought to transcend the experience of a single individual, instead intertwining multiple voices to construct a narrative.

This approach also helped us to overcome some of the ethical problems associated with ethnographic self-revelations that may be hurtful or harmful to others. A number of people with whom we shared our stories expressed an interest in trying to identify characters in them based on individuals that they knew. Others were reluctant to give consent to our incorporation of their experiences into an article because of concerns that this might damage their relationships or that they would be identifiable. The construction of composite vignettes helped to overcome some of the difficulties associated with the sensitivity of the topic we were exploring.

We then analysed our stories thematically, looking for common and contradictory patterns and developing conceptual categories that formed the basis for our interpretations and selecting particular vignettes that exemplified our emerging themes for presentation in this article. Although this method of data collection and analysis does not overcome the limitations associated with our different subject positions as members of the community (one of us is male the other female, one is employed in a teaching-led and the other in a research-led business school), it reduces the potential for narcissism that can sometimes be associated with such a project (Coffey, 1999) and enables us to build up a picture of practices of cultural inscription that goes beyond our direct experience.

Our writing strategy draws on techniques of performative or creative writing as a way of involving the reader in a text that is more vivid and immediate (Caulley, 2008; Pelias, 2005). Performative writing starts "with the recognition that individual bodies provide a potent database for understanding the political and that hegemonic systems write on individual bodies' (Pelias, 2005: 420). We use an active voice to evoke the sense of perceptions and thoughts as they unfolded with the purpose of generating moments that the reader can enter into and identify with (Davies et al., 2005). We keep the identity of the narrator gender-neutral to give the reader as much latitude as possible in reading themselves into the text, presenting these fragments or moments in a way which invites others to connect with them.

\section{Conferences as a site of body pedagogics}

In contrast to many activities through which academic identities are formulated, such as writing, which usually take place out of the presence of an audience, conferences are an arena in which the academic's embodied presence is required as a prerequisite of face-to-face interaction. Goffman (1972: 1) describes week-long conferences as 'interactional mastodons that push to the limit what can be called a social occasion'. For a few days all human activities, including working, eating and sleeping, are carried out in the same limited space in the presence of a large number of others who are all treated alike and encouraged to do the same thing together (Goffman, 1961). Through their unfamiliarity with the local context and removal of familiar objects and relationships that help to sustain an individual's sense of self, participants are spatially and symbolically separated from the outside world. The way that individuals inhabit and use the organized space of the conference is also significant in constituting embodied subjectivity. This includes how delegates move about, 'what they do with their bodies, where they go and how they walk, who they stand near or move away from, who they seek out and who they ignore' (Halford and Leonard, 2006: 98). Conferences are thus a central site in which embodied work is performed. 
Recent sociological studies have demonstrated how in various occupations, including soldiers (Lande, 2007), ballet dancers (Aalten, 2007) and glass-blowers (O'Connor, 2007), bodily practices constitute an important means of communicating values by 'anchoring norms and beliefs in viscera' (Lande, 2007: 97). The concept of body pedagogics is useful in enabling a focus on 'the central pedagogic means through which a culture seeks to transmit its main corporeal techniques, skills and dispositions, the embodied experiences associated with acquiring or failing to acquire these attributes, and the actual embodied changes resulting from this process' (Shilling, 2007: 13, emphasis in original). The body is thus the medium through which socialization into a culture is achieved through a pedagogic process of teaching and learning. It constitutes a receptive surface and the discursive object onto which an ideological construction of the proficient CMS academic is written (Grosz, 1994).

In order to understand the role of bodily inscription in constituting the academic subject, it is necessary to investigate how body techniques are taught and the experiences people go through in acquiring them. Conferences provide an inter-corporeal space and a central pedagogic means through which the bodily techniques, skills and dispositions associated with becoming a proficient CMS academic are transmitted. Through participating in conferences, the embodied agent learns appropriate ways of using her body as a means of demonstrating proficiency. The remainder of this section explores the institutionalized body pedagogics that characterize CMS culture and considers the power relations and normative content that informs them. By describing situations in which the bodily dispositions of control and endurance are made explicit, the ethical values of the culture are highlighted.

\section{Control}

Conferences are an important context in which academics learn how to perform in a controlled manner in front of an audience (Goffman, 1971). A person's style of speaking, their movements and reactions have the potential either to affirm or undermine this status. Presenting oneself convincingly entails the projection of 'front' and involves a high degree of stage-craft for the performer to convince the audience that they incorporate and exemplify the values of the culture. The setting for performances is fixed. The performer stands or sits at the front of a room facing a seated audience and uses a series of props such as overhead slides. The performer's manner alerts the audience to the interactional role they expect to play. An aggressive manner indicates that they expect to lead the interaction, whereas a meek, apologetic one suggests they expect to follow the lead of others. Less experienced performers are more likely to encounter doubts from co-participants concerning the 'realness' of what is presented and initially even they may not be taken in by their own routine. In these circumstances 'speakers can feel on trial, their whole career and identity at stake' (Stanley, 1995: 172).

I'm feeling scared. It is my first CMS conference and I have no idea what to expect. The room is small, packed with people and hot. I've been sitting here for an hour and a half now, waiting for my turn. I look at the clock as it ticks away towards and then past the time I'm meant to present. I feel a simultaneous sense of fear-wanting to be sick, run away and hide-and anger-I want to go up and kick the current presenter who seems completely oblivious to having taken up more than his allotted time. Suddenly he stops. I nervously make my way to the front and I notice that about half of the audience are leaving. I feel hurt and embarrassed. They must think I am not worth listening to. Those remaining are looking at me. I recognise one of the faces at the back as a famous professor whom I've only seen in photos before. Is he going to listen to me? I feel the tension cripple my body. I look around the room for a familiar face. There are none. I smile, pretend to be confident and start to speak. My voice wobbles. As the presentation 
continues I begin to feel a little better. I finish speaking and ask if there are any questions. A few people raise their hands. The first question is ok. Then the professor at the back starts, without being invited, to ask a question. He says I have got the theory wrong. He goes on to criticise other aspects of my work. I feel like crying, my head is clouded with confused thoughts. I feel my face flushing. How can I ever answer these questions? I'm not good enough to be an academic. As the session ends a couple of people come up to me and tell me not to worry about the professor at the back, 'he always does that, he likes to intimidate new researchers'. 'Don't worry' they say, 'we thought your presentation was good'. I feel relieved.

As performers become more familiar with the rules, they are likely to become more convinced that the impression they stage is genuine. A convincing performance relies on the maintenance of expressive control and the avoidance of minor cues or unmeant gestures that could undermine this. The rules of conference participation train individuals in corporeal techniques that enable the concealment of inappropriate emotions such as fear, anxiety, vulnerability and nervousness and ensure the presentation of confident, capable selves. Bodily signs of fear or anxiety, such as blushing, sweating, shaking or crying, must be suppressed, even if the feelings experienced-anger, hurt, pain, loneliness, excitement and frustration-are extremely intense (Ford and Harding, forthcoming; Stanley, 1995). Undergoing this experience has powerful productive effects. Humphreys (2005) suggests that conference presentation constitutes an important rite of passage in which one's emotional frailties must be hidden behind a mask of certainty and clear direction-intimidating rather than intimidated, dominating rather than dominated. Although Humphrey's comments relate to a mainstream management studies conference, we suggest these bodily techniques are equally prevalent within CMS. However, the concealment of emotion is a disposition principally reserved for public performances. In back regions, individuals may resist these practices by caring for each other and providing mutual emotional support. Yet the location of these practices outside the front region where performances are learned suggests that this represents a safety-valve that enables individuals to endure these practices, rather than a means of challenging them.

\section{Endurance}

Conferences also enable the transmission of the bodily attribute of endurance through development of a disposition of physical fortitude in a context where intense work-related pressures are combined with disruption to physical routines. The ability to withstand discomfort or suffering caused by hunger, fatigue or alcohol constitutes a key attribute in the training of the proficient CMS academic. Corporeal discomfort affects the subject in different ways. Some embrace it as a means of demonstrating their durability in a way that is similar to the initiation rituals that characterize socialization into cultures of masculinity in industrial workplaces (Collinson, 1992). Others are more resistant to these practices, instead seeking out possibilities of escape, however temporary, from predictable scripts and standardized patterns of behaviour, for example by taking time out to go sightseeing or spend time with outsiders.

I am standing in a large room with around two or three hundred other people, a glass of warm white wine in my hand. The noise of voices is overwhelming. I feel sweat running down the backs of my legs. The professor I am talking to asks me who else works at my university. I reel off a few names of colleagues in the business school but his eyes quickly glaze over and from time to time he looks over my shoulder and across the room. Is he looking for someone? Maybe he would just rather not be talking to me. Next he begins to ask me about my research. I feel annoyed and scrutinized. Do I still have to carry on performing even now? When does it ever stop? I don't want to do my 'these are my research interests' speech 
again. I am saved as suddenly he excuses himself and moves away to talk to someone else. I feel relieved, followed by a gaping hole of loneliness as I realise I am standing completely alone in the middle of the room. I start to wander around, squeezing past groups of people talking and laughing. I feel small. Everyone else seems to know each other. I try not to look at people's faces, instead reading name badges without the catching the wearer's eye. I am hungry and it's getting late. Some crumbs and wilted salad garnish is all that remains on the platters in the centre of the room now that the press of bodies around them has subsided enough for me to get near. I am tired from travelling and presenting my paper and I still have indigestion from lunch. A dull headache starts to creep slowly across my forehead, the result of too much coffee and too little water. Perhaps the best thing to do is just go to bed and try to get some sleep, as long as I can find my room again. Is this what it means to be an academic?

Failure to acquire the attribute of endurance impacts negatively on the subject's ability to become a full member of the culture. This is evident from drinking rituals which involve participants exercising their corporeal skill in enduring and withstanding the effects of alcohol. Far from being incidental to the conference proceedings these situations are recognized as a context where working partnerships are formed and renewed, ideas are discussed and joint academic projects developed. Contrary to the espoused informality and supportiveness of such occasions, they are highly charged with the exercise of academic power. Physical endurance is further reinforced by the telling of drinking stories, anecdotes or comments in formal conference sessions that typically refer to an earlier episode of heavy drinking. Whilst not everyone participates in these bodily practices, many finding alternative sub-groups to socialize with or withdrawing from the social aspects of the conference altogether, their existence provides insight into the construction of the proficient CMS academic as an embodied subject.

Similar gendered practices have been observed in other masculine organizational cultures where the development of social networks involves getting 'ratted with the boys in the pub' (female respondent quoted in McDowell, 1997: 154). These practices gender CMS culture in a way that inherently favours masculine identities and bodies and is symbolic of masculine power; thus 'it hardly takes a sophisticated feminist critique to realize that British critters are a bit too blokeish to be inclusive' (Rowlinson and Hassard, 2008: 4). CMS's adoption of a coherent, preconceived, rebellious identity in opposition to the dominant culture of mainstream management studies (Reedy, 2008; Worthington and Hodgson, 2005) may further discourage examination of these practices.

\section{Silencing the body}

Every academic community develops its own culture (Becher and Trowler, 1989), the people who belong to it sharing certain values and acting according to certain rules that guide their behaviour. Through our analysis of the bodily dispositions of control and endurance involved in becoming a proficient CMS academic we have sought to make the role of the body as the medium of socialization into this culture more explicit. In this section we consider the ethical beliefs and values that inform these body pedagogics and their potential silencing effects on individuals and groups.

Within CMS the body is treated as an object of secondary importance to the mind, its concealment giving rise to the possibility of neglect. The proficient CMS academic learns to cultivate her dispassionate, disembodied mind by subordinating her volatile, emotional body. These dispositions are informed by a Western philosophical tradition that divorces and privileges mind over body, reason over emotion, in a way which is supportive of gendered Cartesian boundaries (Knights and Thanem, 2005). These dispositions are also informed by a conceptualization of academic work as a vocation which the individual is called to do, not as a means to an end, but an activity that requires total and passionate commitment and involves an element of physical and 
spiritual suffering (Weber, 1917). This gives rise to the potential for participants to become estranged from their bodies, self-estrangement constituting the basis for estrangement from one another (Martin, 2000).

The marginalization of the body has implications for power relations and ethics within CMS related to the patriarchal cultural association of the sexed, emotional body with subordinated groups, particularly women. These bodily dispositions may be interpreted as symptomatic of a 'between-men' culture which, although it claims to be universal, is organized according to male genealogical systems (Irigaray, 2007: 13). Between-men cultures are structured hierarchically in a way that excludes difference. In such a context, the feminine becomes the non-masculine, an abstract non-existent reality which is made to disappear. Women are thereby excluded and required to subject themselves to the imperatives of a patriarchal culture that alienates their female identity. Rather than seeking to neutralize gender, Irigaray argues for a revised conception of sexed difference as rooted in biology and culture, as a means through which women can gain recognition for their difference and gain a subjective status equivalent to men. Thus she argues there is a need to valorize the feminine gender once more, rather than assimilate it.

The opposition between male and female is inextricably linked to the binarized conception of mind and body, recognition of the former therefore entails acknowledgement of the latter. However, as this article has shown, there is little explicit acknowledgement of these embodied practices within CMS. This appears to constitute a situation 'whereby a group of people tacitly agree to outwardly ignore something of which they are all personally aware' (Zerubavel, 2006: 2). Such a situation presupposes denial is to an extent collective, relying on the deliberate effort of members of a given social system to jointly refrain from acknowledging them. The metaphor of the elephant in the room represents the object of such conspiracies, which are so conspicuous in demanding attention that significant effort is required to avoid noticing them. It is a further intention of this article to prompt others to share their embodied experiences of the culture and the values that inform these bodily dispositions, the quotes that follow representing an attempt at extending this dialogue.

I used to feel that the all-encompassing nature of (critical) academic work was 'a good thing' in that it denied traditional divisions of public and private, and perhaps the idea that one's real self was the self at leisure. I'm much more troubled about it now. (Mid-career male academic)

As for the heavy drinking of beer and the failure to distinguish work from leisure. Mea culpa. The former is fun, sometimes, but the latter is bad manners, sometimes. At the same time, I always wanted to do something that I cared about enough to write emails at 22.12, so there it is. (Senior male academic)

Other individuals suggest that, although these bodily practices can be observed and experienced at other management studies conferences, they are more exaggerated at CMS conferences:

The 'right-on' attitudes of CMS lead many of its supporters to think they're automatically supportive of women, more junior academics, and any oppressed group. It's harder to get through to such people the fact that their acts betray their intentions. What is worrying is that some of the up and coming generation of CMS theorists are more macho than the parental figures they're trying to overthrow... Some male academics who are friends, so who will talk openly (after a few glasses of wine), admit to finding conferences traumatic - hence their need to wander round in packs... We all know some faces that we see coming into our presentation-who regard any academic giving a paper in the same way that a cat does a mouse: to be trifled with and teased until the kill. I've been to some CMS seminars that were really warm and supportive and significant in that certain names and faces were absent. (Mid-career female academic) 
Despite the ideological commitment of CMS to challenging oppressive practices in other organizational contexts it seems there is limited reflexivity concerning the potential silencing effects of these bodily practices. However, acceptance is by no means universal. Some individuals employ coping strategies including partial or non-participation in the conferences:

I loathe attending conferences... I enjoy them less now (despite now having many relationships with colleagues with whom I feel comfortable) than I used to (when I knew very few people). I almost never go to conferences any more-this CMS will be the first for almost two years and the last for another year... [The last CMS conference] reminded me why I've almost ceased going to conferences. There seemed to be a degree of general nastiness in the air in some sessions and conversations-more than I'd experienced (or anyway noticed) before, and a couple of people seemed to go out of their way to be very hostile to me (both face-to-face and I was told behind my back), which upset me a lot. (Mid-career male academic)

As this final comment highlights, theoretical sensitivity to power relations does not necessarily prevent participation in practices that are excluding to others or translate into a commitment to transform oppressive, exclusionary practices (Cockburn, 1988; Fay, 1987; Kleinman, 1996).

\section{Conclusion}

Before we can discuss what people think or value about their worlds, we need to consider how the articulation of their bodies acts as the foundation for those beliefs and values. (Lande, 2007: 97)

Conferences are an inter-corporeal space wherein academic identities are constructed through embodied experience. This entails the acquisition of skills and dispositions that enable newcomers to demonstrate their proficiency as members of a culture. 'Knowing-how-to-be' a proficient CMS academic is founded on a process of bodily learning, the bodies of participants comprising the surface onto which the culture inscribed, becoming emblems (Grosz, 1994) that exemplify and embody its ethics and values. In addition to its superficial effects this generates a particular subjectivity and a moral interiority by inscribing the culture onto the body.

Through introducing the body into debates about what constitutes CMS this article may be interpreted as an attempt towards critical performativity (Spicer et al., 2009), through inviting reconsideration of the practical activities through which ideological aims may be realized. However, rather than emphasizing critical intervention in managerial discourses and practices, this article has focused on academic discourses and practices. Much of the debate surrounding CMS has so far focused on its role as an intellectual, pedagogical and/or political project. However, we suggest that change also depends on changing the identity formation of the embodied subject (Irigaray, 2007). The need for socio-economic reform should therefore not be placed above the need for transformed internal cultural relations and the development of cultures of difference within CMS.

Self-reflexive critique is essential to this process of development. Through exploring our own embodied participation in CMS conferences and the reactions of others, we have sought to gain insight into the power relations and normative content that inform these bodily practices. We have been guided in this analytical task by the notion that 'some questions are productive to embrace because they connect individuals, not just as scholars, but as people who are willing to place themselves at personal risk... In doing so, what might have remained hidden is made public, what might have stayed buried is put under examination, what might have been kept as personal commitment becomes public testimony' (Pelias, 2005: 421). 
To conclude, we offer a few practical suggestions for the development of a more embodied understanding of the nature of belonging within CMS:

1. Develop cultural customs that challenge the male right to make noise, materially and spiritually and enable women and other subordinate groups to speak and be heard. This would involve both men and women at conferences learning 'how to remain silent, calm, and to speak quietly... be attentive to others, modest and patient' (Irigaray, 2007: 58).

2. Rethink the role of conferences as a collective learning space by acknowledging the role of the feeling body as well as the rational mind in this process (Edenius and Yakhlef, 2007). This could involve reshaping the physical environment in ways that disrupt established practices. It might also involve conducting 'breaching experiments' (Garfinkel, 1967) to encourage people to fully describe the informal rules and taken-for-granted methods that characterize embodied participation.

3. Explore alternative ways of doing conferences, such as 'unconferencing' (Wolf and Troxler, 2008) and 'open space technology' (Owen, 2008), as models for collective learning that are less hierarchically structured, thereby potentially promoting a more dialogic, creative engagement.

4. Move away from the ethic of attack, destruction and demolition of the personhood of others (Spicer et al., 2009) towards an ethic based on interconnectedness, nonviolence and care (Gilligan, 1982). This would involve developing an awareness and sensitivity to one's own embodied selfhood as a precondition of caring for others.

5. Develop spaces for women and other subordinate groups to express difference within CMS conferences, rather than seeking their assimilation into the dominant culture. This would involve according positive value to alternative forms of corporeal identity and exploring the relationships that subordinate groups within CMS have with the dominant culture and each other.

We do not see this as an opportunity to win an argument, colonize a debate, claim an intellectual territory, or impose our logic on others. We cannot speak without promoting our own vested interests, personal histories, philosophical and theoretical assumptions. Furthermore, it is an inescapable aspect of human embodiment that seeing and knowing are perspectival. We always see from the points of view invested with personal as well as political meaning: a degree of centricism is inescapable. There is also a danger that we seek to salve our consciences through revealing our awareness of the disciplinary practices in which we participate. Notwithstanding, we believe that our experiences and analysis are worth writing about, if only to make these issues more explicit.

Finally, these arguments also have implications for the study of other professional groups whose members are socialized through attending conferences, including managers (Ford and Harding, 2008). Studies of organizational culture have traditionally focused on the symbolic and discursive practices through which values, beliefs and norms are established and communicated (Casey, 1995; Gagliardi, 1990; Kunda, 1992; Watson, 1994). This article has argued that to understand how members of a culture collectively learn a set of shared values and rules of conduct we must also enter the actor's body. Understanding culture is thus not just about words, but also about conduct and the 'embodied dispositions it demands and nurtures' (Wacquant, 2005: 466). This is particularly relevant to understanding our own organizational culture, for if we cannot learn from ourselves we are likely to find ourselves in a weaker position from which to understand the cultures of others. 


\section{References}

Aalten, A. (2007) 'Listening to the Dancer's Body', in C. Shilling (ed.) Embodying Sociology: Retrospect, Progress and Prospects, pp. 109-25. Oxford: Blackwell/ Sociological Review.

Alvesson, M. (2003) 'Methodology for Close Up Studies: Struggling with Closeness and Closure', Higher Education 46(2): 167-93.

Alvesson, M. and Sköldberg, K. (2000) Reflexive Methodology: New Vistas for Qualitative Research. London: Sage.

Becher, T. and Trowler, P. (1989) Academic Tribes and Territories: Intellectual Enquiry and the Cultures of Disciplines. Milton Keynes: Society for Research into Higher Education/Open University Press.

Blaxter, L., Hughes, C. and Tight, M. (1998) The Academic Career Handbook. Buckingham: Open University Press.

Brannick, T. and Coghlan, D (2007) 'In Defense of Being "Native”: The Case for Insider Academic Research', Organizational Research Methods 10(1): 59-74.

Burrell, G. (1993) 'Eco and the Bunnymen', in J. Hassard and M. Parker (eds) Postmodernism and Organization, pp. 71-82. London: Sage.

Butterwick, S. and Dawson, J. (2005) 'Undone Business: Examining the Production of Academic Labour', Women's Studies International Forum 28: 51-65.

Casey, C. (1995) Work, Self and Society: After Industrialism. London: Routledge.

Caulley, D. N. (2008) 'Making Qualitative Research Reports Less Boring: The Techniques of Writing Creative Non-Fiction', Qualitative Inquiry 14(3): 424-49.

Clegg, S., Kornberger, M., Carter, C. and Rhodes, C. (2006) 'For Management?', Management Learning 37(1): 7-27.

Cockburn, C. (1988) 'Masculinity, the Left and Feminism', in R. Chapman and J. Rutherford (eds) Male Order: Unwrapping Masculinity, pp. 303-29. London: Lawrence and Wishart.

Coffey, A. (1999) The Ethnographic Self: Fieldwork and the Representation of Identity. London: Sage.

Collinson, D. (1992) Managing the Shopfloor: Subjectivity, Masculinity and Workplace Culture. New York: Walter de Gruyter.

Davies, B., Browne, J., Gannon, S., Honan, E. and Somerville, M. (2005) 'Embodied Women at Work in Neoliberal Times and Places', Gender, Work and Organization 12(4): 343-62.

Edenius, M. and Yakhlef, A. (2007) 'Space, Vision and Organizational Learning: The Interplay of Incorporating and Inscribing Practices', Management Learning 38(2): 193-210.

Ellis, C. (2004) The Ethnographic I: A Methodological Novel About Autoethnography. Walnut Creek CA: Alta Mira Press.

Ellis, C. (2007) 'Telling Secrets, Revealing Lives: Relational Ethics in Research With Intimate Others', Qualitative Inquiry 13(1): 3-29.

Ellis, C. and Bochner, A. P. (1992) 'Telling and Performing Personal Stories: The Constraints of Choice in Abortion', in C. Ellis and M. Flaherty (eds) Investigating Subjectivity: Research on Lived Experience, pp. 79-101. Newbury Park, CA: Sage.

Ellis, C. and Bochner, A. P. (2000) 'Autoethnography, Personal Narrative, Reflexivity: Researcher as Subject', in N. Denzin and Y. Lincoln (eds) Handbook of Qualitative Research, pp. 733-68. London: Sage.

Fay, B. (1987) Critical Social Science. Cambridge: Polity Press.

Ford, J. and Harding, N. (2008) 'Fear and Loathing in Harrogate, or a Study of a Conference', Organization 15(2): 233-50.

Ford, J. and Harding, N. (forthcoming) 'Get Back into that Kitchen Woman: Management Conferences and the Making of the Female Professional Worker', Gender, Work and Organization. 
Fournier, V. and Grey, C. (2000) 'At the Critical Moment: Conditions and Prospects for Critical Management Studies', Human Relations 53(1): 7-32.

Fulop, L. (2002) 'Practising What You Preach: Critical Management Studies and its Teaching', Organization 9(3): 428-36.

Gagliardi, P. (1990) Symbols and Artifacts: View of the Corporate Landscape. New York: Aldine de Gruyter. Garfinkel, H. (1967) Studies in Ethnomethodology. Englewood Cliffs, NJ: Prentice Hall.

Gilligan, C. (1982) In a Different Voice. Cambridge, MA.: Harvard University Press.

Goffman, E. (1961) Asylums. Garden City, NJ: Anchor Books.

Goffman, E. (1971) The Presentation of Self in Everyday Life. London: Penguin.

Goffman, E. (1972) Interaction Ritual. London: Penguin.

Grosz, E. (1994) Volatile Bodies: Toward a Corporeal Feminism. Bloomington, IN: Indiana University Press.

Halford, S. and Leonard, P. (2006) Negotiating Gendered Identities at Work: Place, Space and Time.

Basingstoke: Palgrave Macmillan.

Hayano, D. (1979) 'Auto-Ethnography: Paradigms, Problems and Prospects', Human Organization 38(1): 99-104.

Humphreys, M. (2005) 'Getting Personal: Reflexivity and Autoethnographic Vignettes', Qualitative Inquiry 11(6): 840-60.

Humphreys, M. and Learmonth M. (2009) 'Public Sector Management? But We're Academics, We Don't Do That Sort of Thing!', in G. Currie, J. Ford, N. Harding and M. Learmonth (eds) Public Sector Management: A Critical Approach. London: Routledge (in press).

Irigaray, L. (2007) Je, Tu, Nous: Toward a Culture of Difference. London: Routledge.

Kleinman, S. (1996) Opposing Ambitions: Gender and Identity in an Alternative Organization. Chicago, IL: University of Chicago Press.

Knights, D. (2006) ‘Authority at Work: Reflections and Recollections', Organization Studies 27(5): 699-720.

Knights, D. and Thanem, T. (2005) 'Embodying Emotional Labour', in D. Morgan, B. Brandth and E. Kvande (eds) Gender, Bodies and Work, pp. 31-43. Aldershot: Ashgate.

Kunda, G. (1992) Engineering Culture: Control and Commitment in a High-Tech Corporation. Philadelphia, PA: Temple University Press.

Lande, B. (2007) 'Breathing Like a Soldier: Culture Incarnate', in C. Shilling (ed.) Embodying Sociology: Retrospect, Progress and Prospects, pp. 95-108. Oxford: Blackwell/ Sociological Review.

Lodge, D. (1985) Small World: An Academic Romance. London: Penguin Books.

McCloskey, D. (1999) Crossing: A Memoir. Chicago, IL: University of Chicago Press.

McDowell, L. (1997) Capital Culture: Gender at Work in the City. Oxford: Blackwell.

Martin, J. E. (2000) Coming of Age in Academe: Rekindling Women's Hopes and Reforming the Academy. New York: Routledge.

New, C. and Fleetwood, S. (2006) 'Gender at Critical Realism Conferences', Journal of Critical Realism 5(1): 61-91.

O'Connor, E. (2007) 'Embodied Knowledge in Glassblowing: The Experience of Meaning and the Struggle Towards Proficiency', in C. Shilling (ed.) Embodying Sociology: Retrospect, Progress and Prospects, pp. 126-41. Oxford: Blackwell/ Sociological Review.

Owen, H. (2008) Open Space Technology: A User's Guide. San Francisco, CA: Berrett-Koehler.

Parker, M. (2002) Against Management: Organization in the Age of Managerialism. Cambridge: Polity Press. Pelias, R.J. (2005) 'Performative Writing as Scholarship: An Apology, an Argument, an Anecdote', Cultural Studies, Critical Methodologies 5(4): 415-24.

Reedy, P. (2008) 'Mirror, Mirror, on the Wall: Reflecting on the Ethics and Effects of a Collective Critical Management Studies Identity Project', Management Learning 39(1): 57-72. 
Reynolds, M. (1999) 'Grasping the Nettle: Possibilities and Pitfalls of a Critical Management Pedagogy', British Journal of Management 10(2): 171-84.

Reynolds, M. and Trehan, K. (2001) 'Classroom as Real World: Propositions for a Pedagogy of Difference', Gender and Education 13(4): 91-109.

Riemer, J. (1977) 'Varieties of Opportunistic Research', Urban Life 5: 467-77.

Rowlinson, M. and Hassard, J. (2008) 'How come the Critters Came to be Teaching in Business Schools?

Sociology, Politics and Punk Rock', Critical Management Studies Seminar Series, February, Manchester. Rugg, G. and Petre, M. (2004) The Unwritten Rules of PhD Research. Maidenhead: Open University Press.

Shilling, C. (2007) 'Sociology and the Body: Classical Traditions and New Agendas', in C. Shilling (ed.) Embodying Sociology: Retrospect, Progress and Prospects, pp. 1-18, Oxford: Blackwell/ Sociological Review.

Showalter, E. (2005) Faculty Towers: The Academic Novel and its Discontents. Oxford: Oxford University Press.Spicer, A. (2005) 'Conferences', in C. Jones and D. O'Doherty (eds) Manifestos for the Business School of Tomorrow, pp. 21-7. Abo, Finland: Dvalin Books.

Spicer, A., Alvesson, M. and Kärreman, D. (2009) 'Critical Performativity: The Unfinished Business of Critical Management Studies', Human Relations 62(4): 537-60.

Spradley, J. P. and McCurdy, D. W. (1973) The Cultural Experience: Ethnography in Complex Society. Chicago, IL: Science Research Associates.

Stanley, J. (1995) 'Pain(t) for Healing: The Academic Conference and the Classed/Embodied Self', in L. Morley and V. Walsh (eds) Feminist Academics: Creative Agents for Change, pp. 169-82. London: Taylor \& Francis.

Van Maanen, J. (1988) Tales of the Field: On Writing Ethnography. Chicago, IL: University of Chicago Press. Wacquant, L. (2005) 'Carnal Connections: On Embodiment, Apprenticeship and Membership', Qualitative Sociology 28(4): 445-74.

Walsh, J. P. and Weber, K. (2002) 'The Prospects for Critical Management Studies in the American Academy of Management', Organization 9(3): 402-10.

Watson, T. (1994) In Search of Management: Culture, Chaos and Control in Managerial Work. London: Routledge.

Weber, M. (1917) The Vocation Lectures: Science as a Vocation, Politics as a Vocation. Indianapolis, IN: Hackett Publishing.

Wolf, P. and Troxler, P. (2008) 'The Proof of the Pudding is in the Eating—but What was the Pudding in the First Place? A Proven Unconferencing Approach in Search of its Theoretical Foundations', FQS Forum: Qualitative Social Research 9(2) Art. 61.

Worthington, F. and Hodgson, J. (2005) 'Academic Labour and the Politics of Quality in Higher Education: A Critical Evaluation of the Conditions and Possibility of Resistance', Critical Quarterly 47(1-2): 96-110. Wray-Bliss, E. (2003) 'Research Subjects/Research Subjections: Exploring the Ethics and Politics of Critical Research', Organization 10(2): 307-25.

Wray-Bliss, E. (2004) 'A Right to Respond? Monopolisation of 'Voice' in CMS', Ephemera 4(2): 101-20.

Zerubavel, E. (2006) The Elephant in the Room; Silence and Denial in Everyday Life. Oxford: Oxford University Press. 